\section{A Study of Oxygenation Techniques and the Chlorophyll Responses of Pelargonium tomentosum Grown in Deep Water Culture Hydroponics}

\author{
Joshua D. Butcher ${ }^{1}$, Charles P. Laubscher, and Johannes C. Coetzee \\ Faculty of Applied Sciences, Cape Peninsula University of Technology, P.O. \\ Box 1906, Bellville, Cape Town 7535, Western Cape, South Africa
}

Additional index words. hydroponic nutrient solution, deep water culture (DWC), vortex oxygenation, chlorophyll fluorescence ratio, dissolved oxygen (DO)

\begin{abstract}
Pelargonium tomentosum Jacq.; the peppermint-scented pelargonium, is an herbaceous groundcover indigenous to the Western Cape of South Africa. Volatile oils are produced by this plant, which are used in the fragrance industry. Studies on other Pelargonium species have shown chlorophyll content may affect the yield of essential oils. This study was carried out to investigate the viability of growing $P$. tomentosum in deep water culture (DWC) hydroponics and how best to aerate/oxygenate the nutrient solution to increase the chlorophyll content within leaves. The experiment was conducted over a period of 74 days, 16 different methods of oxygenation were applied to 9 replicates. The control had passive aeration; the treatments were made up of air-pumps, vortex oxygenators, and the application of hydrogen peroxide at various frequency intervals; these were combined with each other and run as separate oxygenation methods. The measurement of the chlorophyll content of plant leaves has been established to be an accurate way of establishing vigor, health, and levels of stress. It was found that the combination of high-frequency application (every third day) of hydrogen peroxide, vortex oxygenation, and air-pump injection (both operational for 24 hours/day) which formed treatment 11 (APVHa), yielded the highest production of chlorophyll within all the replicates differing significantly $(P \leq 0.001)$ from the control and other treatments.
\end{abstract}

Chlorophyll is vital for the process of photosynthesis to occur in both higher and lower plants (Konica Minolta, 2015). Chlorophyll is an accumulation point for increased levels of nitrogen in plants, observation of the chlorophyll content within a leaf can be indicative of a plant's ability to take up nitrogen, the development of chloroplasts, and thus photosynthetic capability. Measurement of chlorophyll content can provide information regarding the overall health of a plant (Ling et al., 2011; Marsh, 2016).

\section{Chlorophyll Fluorescence}

Light energy which is not absorbed by leaves to drive photosynthesis dissipates as heat or is reemitted as fluorescence (Maxwell and Johnson, 2000). Due to the different wavelengths at which light is reemitted as fluorescence to those which are absorbed by a leaf (described by the Kautsky effect), the level of photosynthesis (photochemistry) can be observed and the content of chlorophyll within a leaf ascertained (Maxwell and Johnson, 2000). Not only has observation of chlorophyll within plants provided researchers insight into the stress levels experienced in certain environments but also into quality of water used for irrigation and the

${ }^{1}$ Corresponding author. E-mail: joshuabonesbutcher@ gmail.com effects of fertilizer application (Schlemmer et al., 2005; YSI, 2015). The proliferation of easy-to-use chlorophyll fluorometers over the decades preceding this study has made chlorophyll fluorescence a widely investigated parameter in scientific botanical research in both laboratory and field studies (Ling et al., 2011; Manetas et al., 1998; Maxwell and Johnson, 2000; van Kooten and Snel, 1990).

\section{The Role of Oxygen $\left(\mathrm{O}_{2}\right)$ in Plant Growth}

$\mathrm{O}_{2}$ plays a vital role in plant metabolic processes (Zheng et al., 2007); respiration requires oxygen to be carried out effectively. It can be taken up through the stomata within the leaves or via the root system (Douglas, 1970). In land plants, $\mathrm{O}_{2}$ deficiency has a rapid deleterious effect on the ability of roots to absorb water and other essential compounds (Urrestarazu and Mazuela, 2005). Although glycolysis does not depend solely on the presence of $\mathrm{O}_{2}$ (Salisbury and Ross, 1985); when there is an absence of $\mathrm{O}_{2}$, the resultant pyruvate and nicotinamide adenine dinucleotide will accumulate resulting in anaerobic respiration.

\section{Oxygenation in Hydroponics}

Plant growth has been shown to increase when irrigated with additional dissolved oxygen (DO) in the solution (Soffer et al., 1990), therefore, in hydroponics it is important that oxygen is dissolved in the solution around the roots of plants. The level of $\mathrm{O}_{2}$ able to be held within the nutrient solution is affected by factors such as water temperature, air pressure, salt content, and purity (Ben-Yaakov and Ben-Asher, 1982; Kepenyes and Váradi, 2015; Morimoto et al., 1989). $\mathrm{O}_{2}$ injection at low pressures using air compressors or pumps into the growing medium has been shown to have some positive trends even in field-grown crops (Chen et al., 2011). There are several established methods of dissolving $\mathrm{O}_{2}$ into hydroponic nutrient solution; these include the formation of droplets through spraying the solution at pressure, creating turbulence or agitation and by gaseous injection with air-pumps (Bonachela et al., 2005; Schröder and Lieth, 2002). Venturi oxygenators, surface agitators, paddles, and counter-flow column gas recyclers are methods mentioned by Kepenyes and Váradi (2015). The size of the bubbles of atmospheric gas which enter the nutrient solution affects plant development; root growth has been shown to be enhanced by the application of microbubbles $(50 \mu \mathrm{m}$ and smaller) compared with macrobubbles which are larger than $50 \mu \mathrm{m}$ (Park and Kurata, 2009). Gaseous bubbles in the nutrient solution contain $\mathrm{O}_{2}$; however, this must be dissolved for submerged plant roots to use it (Bonachela et al., 2005). Air injection by using air-pumps with dispersers has become the conventional method for aerating the solution in hydroponics. These devices have shown beneficial effects on plant growth in hydroponics (Tesi et al., 2003).

Although there are few published findings of oxygenating water by means of vortices, Wójtowicz et al. (2013) found that atomization of water by vortex flow regulators used in waste and storm water management schemes increased DO levels. The effect of a venturi on fluid flow is a decrease in pressure and an increase in velocity, this can facilitate the formation of a visible spinning depression in the fluid (described as a vortex) where air or atmosphere is drawn toward the constriction in the flow apparatus due to the pressure differential. The uniform and predictable mixing of fluids (gas and liquid) created by venturi and the associated vortex formation is used by carburetors within internal combustion engines (Earls, 1997) to ensure efficient fuel/air mixing.

Oxygenation of the solution can also be achieved with the addition of hydrogen peroxide $\left(\mathrm{H}_{2} \mathrm{O}_{2}\right)$ and is commonly applied in hydroponic plant cultivation (Kessler, 2015). $\mathrm{H}_{2} \mathrm{O}_{2}$ is an unstable compound in the molecular sense, when the substance breaks down, one molecule of water is released as well as one highly reactive molecule of oxygen (O-) which either binds to another $\mathrm{O}_{-}$and results in a stable molecule of oxygen (Fredrickson, 2014), or reacts with an organic compound (usually degrading the said compound). The warmer the water gets (above $2{ }^{\circ} \mathrm{C}$ ), the amount of $\mathrm{O}_{2}$ which can be dissolved in the solution is reduced; the resulting combination means an increase of the 
growth of pathogenic microbes (ModularHydro, 2011). The dual function of hydrogen peroxide as an oxygenator and sterilizing agent makes it an attractive option in some cases despite the risk of oxidative stress (Cheeseman, 2007).

\section{Pelargonium tomentosum Jacquin; Peppermint-Scented Pelargonium}

The peppermint scented pelargonium, or Pelargonium tomentosum, is indigenous to South Africa (Lawrence, 2002). Pelargonium tomentosum is an herbaceous groundcover (Height of $0.5 \mathrm{~m}$ ) with a sprawling habit $(1.5 \mathrm{~m})$. Possibly the most remarkable feature of $P$. tomentosum is the prominent peppermintlike scent; the volatile oils and aroma make this a useful therapeutic plant, which is used in the perfume industry. The essential oil secreted by glandular hairs is made up of (-)-isomenthone $(59 \%$ to $62 \%)$ and (+)-methone $(25 \%$ to $33 \%)$, terpenic hydrocarbons make up the remainder (Demarne and Van der Walt, 1990). Production of geranial oil in $P$. graveolens was increased and chlorophyll content was higher after application of 24-epibrassinolide (Swamy and Rao, 2009). Optimal biomass production, photosynthetic rate, and essential oil synthesis was observed in $P$. graveolens when zinc was applied at a rate of $0.025 \mathrm{~g} \cdot \mathrm{m}^{-3}$ (Misra et al., 2005). These findings indicate a possible link between the chlorophyll content and the production of essential oils by this species of Pelargonium. It is possible that increasing the chlorophyll content within $P$. tomentosum could translate to higher yields of valuable essential oil. To date no studies on the effects of oxygenation techniques on $P$. tomentosum have been carried out, this study aims to investigate the growth responses to various methods of oxygenation and aeration in DWC hydroponics by measuring the chlorophyll production within leaves.

\section{Materials and Methods}

Greenhouse experiment. The experiment was conducted in the research greenhouse facility at the Cape Peninsula University of Technology, Bellville, Cape Town, South Africa; GPS co-ordinates-33 ${ }^{\circ} 55^{\prime} 45.53 \mathrm{~S}$, $18^{\circ} 38^{\prime} 31.16 \mathrm{E}$. The nature of the structure in this location ensured control of the environment in which the experiment was conducted. A $40 \%$ Alunet shadecloth was installed $4 \mathrm{~m}$ above the ground level, an additional $40 \%$ polyethylene black shade net was suspended at a height of $2 \mathrm{~m}$ to provide acceptable lighting conditions for the shade-loving plants.

Plant preparation. All the propagation material was procured from a single stock plant of $P$. tomentosum situated in a private garden on the outskirts of Scarborough near to Cape Point, South Africa. Only cuttings taken using homogenous methods were used for the experiment, these were stem cuttings $(\approx 15 \mathrm{~cm}$ long) with a stem thickness of $\approx 9 \mathrm{~mm}$. Two hundred cuttings were made in to ensure that the minimum number of 144 rooted plants were available for the test. Once rinsed with municipal water, the cuttings were placed into propagation trays containing sterile rooting media (Lawrence, 2002) made up of equal parts river sand and perlite to allow for ample drainage. Polystyrene plug trays which allow for isolated rooting to take place were used; these trays were placed onto a hot bed in a climate-controlled glasshouse. The cuttings were sprayed twice weekly with fungicide (BIOGROW COPPER-SOAP, P/ Bag X 15, Suite 115; Hermanus, Western Cape) mixed with municipal water at $20 \mathrm{~mL} \cdot \mathrm{L}^{-1}$ to discourage microbial pathology. After 6 weeks, the cuttings had developed roots and were transplanted into $10-\mathrm{cm}$ plastic pots, the growth media consisted of one part river sand, one part coconut peat, and $1 / 4$ part sifted compost. These plants were placed in a grid layout $50-100 \mathrm{~cm}$ away from an evaporative cooling pad which ensured cool conditions and ample ventilation. The plants were hand watered sparingly, fungicide application continued at the same frequency mentioned previously with the addition of NITROSOL (EFEKTO, Benmore, Johannesburg, Gauteng) at $5 \mathrm{~mL} \cdot \mathrm{L}^{-1}$ of municipal water.

Hydroponic experiment. Once the plants reached the desired degree of homogeneity, they were removed from the $10-\mathrm{cm}$ pots, thoroughly rinsed with municipal water, and transplanted into $12.5-\mathrm{cm}$ pots filled with lightweight expanded clay aggregate or LECA (Galadari Building, Dubai, UAE). LECA was the medium of choice as it is chemically inert, lightweight, and maintains structural integrity (Boudaghpour and Hasemi, 2008) which is ideal for a DWC system. Eleven additional holes of 8-mm diameter had been cut out from the lower third of each pot to allow for root expansion; the pots were placed with their lower portions submerged in the nutrient solution, whereas the upper part of the pots were held in place by the lids of the plastic reservoir containers.

Each treatment had an individual reservoir; ADDIS (Bellville, CT) "Roughtote" 150 -L storage boxes fitted with extra drainage valves were used for this purpose. The hydroponic solution was formed by adding NUTRIFEED (STARKE AYRES Pty. Ltd., Hartebeesfontein Farm, Kempton Park, Gauteng) to municipal water at $90 \mathrm{~g} / 150 \mathrm{~L}$ to achieve an electrical conductivity (EC) ranging from 700 to $1000 \mu \mathrm{S} / \mathrm{cm}$ (Starke Ayres, 2015). EC was measured every third day with an ORBECO HELLIGE (Sarasota, FL) series 150 multiparameter meter.

A randomized block design made up of 16 replicates (each with 9 individual plants) was used in the study. After plants were introduced to the DWC system, a half strength nutrient solution was used to fill the reservoirs to allow for plant acclimatization to the new environment. Treatments began on 15 Apr. 2016, and the experiment was conducted over a period of $74 \mathrm{~d}$. Every $9 \mathrm{~d}$ the system was flushed [i.e., the nutrient solution was renewed (Harris, 1992)]. The $\mathrm{pH}$ of the solution was measured with an ORBECO HELLIGE series 150 multiparameter meter every third day, adjusted and kept within a range of

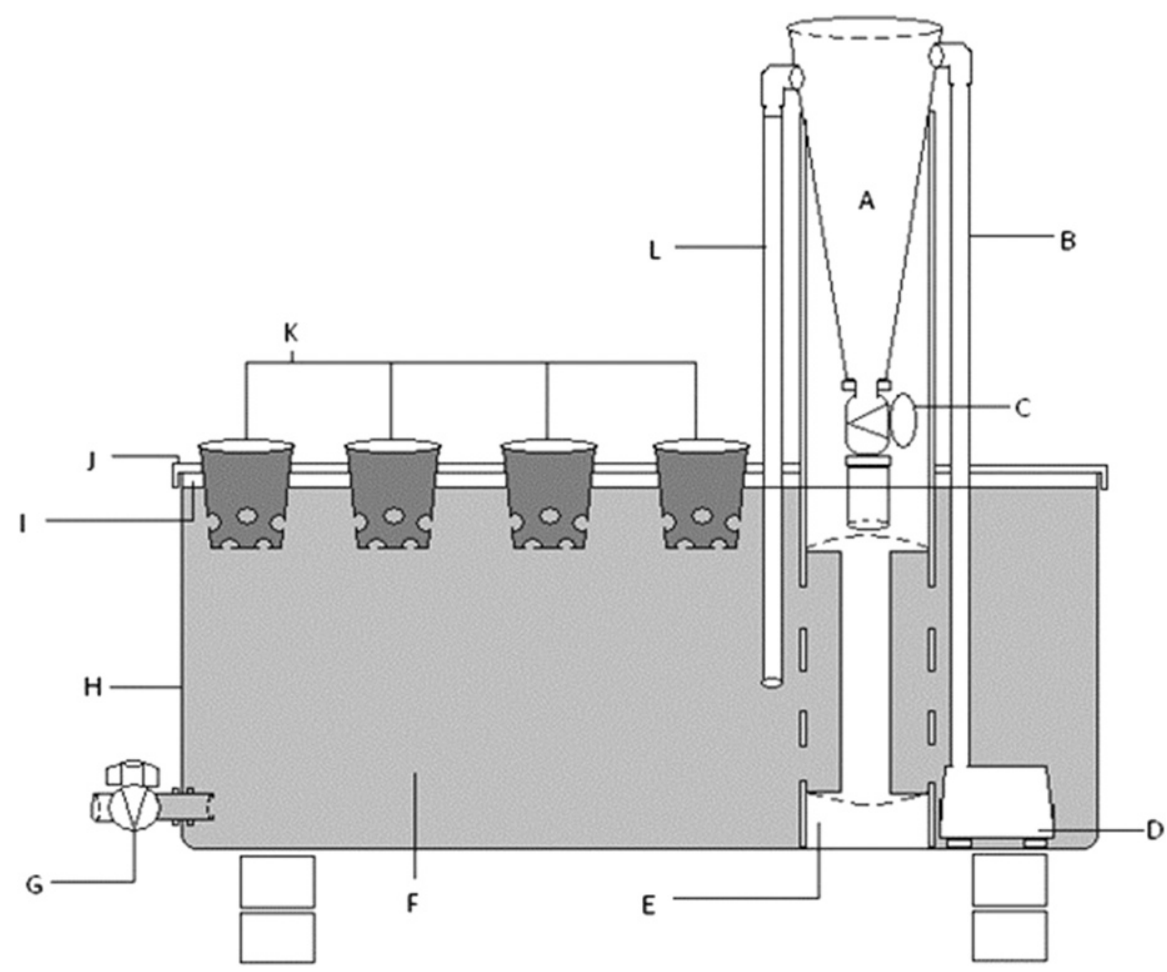

Fig. 1. A schematic diagram of the DWC system with individual components annotated alphabetically, a vortex oxygenation unit is shown on the right-hand side of the diagram. The parts which have been labeled are A: funnel/venturi, B: inlet, C: gate valve (outlet), D: pump, E: PVC support, F: nutrient solution, G: flush-valve, H: reservoir, I: air-gap, J: lid, K: pots, L: over-flow. 
pH 5.5-6.5. Due to the high buffering capacity offered by comparatively large bodies of water, there was little deviation from the range mentioned previously.

Treatment application. The separate treatments comprised of different methods of aerating and dissolving oxygen into the nutrient solution; the treatment codes are followed by their definitions. Each treatment was allocated a number for the purpose of discussion.

1. $\mathrm{C}=$ Passive aeration in the form of gaseous exchange at the surface of the nutrient solution; this is the treatment that was used as the control.

The "Pure" group:

2. $\mathrm{V}=$ Vortex oxygenator.

3. AP $=$ A single air-pump attached to two aquarium aeration stones in the reservoir/sump.

4. APV $=$ Combination of an air-pump with two aquarium aeration stones and a vortex oxygenator.

The "VH" group:

5. $\mathrm{VHa}=$ Vortex oxygenation plus a highfrequency dose of $\mathrm{H}_{2} \mathrm{O}_{2}$.

6 . $\mathrm{VHb}=$ Vortex oxygenation plus a midfrequency dose of $\mathrm{H}_{2} \mathrm{O}_{2}$.

7. $\mathrm{VHc}=$ Vortex oxygenation plus a low-frequency dose of $\mathrm{H}_{2} \mathrm{O}_{2}$.

The "AP" group:

8. $\mathrm{APHa}=\mathrm{A}$ single air-pump attached to two aquarium aeration stones in the reservoir/sump plus a high-frequency dose of $\mathrm{H}_{2} \mathrm{O}_{2}$.

9. $\mathrm{APHb}=\mathrm{A}$ single air-pump attached to two aquarium aeration stones in the reservoir/sump plus a midfrequency dose of $\mathrm{H}_{2} \mathrm{O}_{2}$.

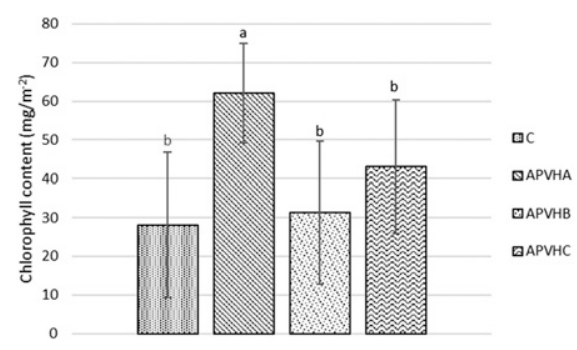

Fig. 2. Effects of treatments $11(\mathrm{APVHa}=$ airpump, vortex oxygenator plus high-frequency dosage of $\mathrm{H}_{2} \mathrm{O}_{2}$ ), 12 (APVHb = air-pump, vortex oxygenator plus midfrequency dosage of $\mathrm{H}_{2} \mathrm{O}_{2}$ ), and 13 (APVHc = air-pump, vortex oxygenator plus low-frequency dosage of $\mathrm{H}_{2} \mathrm{O}_{2}$ ) on the chlorophyll content compared with the control (treatment 1). Bars indicate mean values $\pm \mathrm{SD}$. The mean values represented by the bars annotated with different letters differ significantly at $P \leq 0.001$ as calculated by Fisher's least significant difference. Bars annotated with the same letter are not significantly different. The one-way ANOVA F-statistic is 7.398 .
10. $\mathrm{APHc}=\mathrm{A}$ single air-pump attached to two aquarium aeration stones in the reservoir/sump plus a low-frequency dose of $\mathrm{H}_{2} \mathrm{O}_{2}$.

The "APVH" group:

11. APVHa $=$ Combination of an air-pump with two aquarium aeration stones and vortex oxygenator, plus a highfrequency dose dosage of $\mathrm{H}_{2} \mathrm{O}_{2}$.

12. $\mathrm{APVHb}=\mathrm{Combination}$ of an air-pump with two aquarium aeration stones and vortex oxygenator, plus a midfrequency dose of $\mathrm{H}_{2} \mathrm{O}_{2}$.

13. $\mathrm{APVHc}=\mathrm{Combination}$ of an air-pump with two aquarium aeration stones and vortex oxygenator, plus a lowfrequency dose of $\mathrm{H}_{2} \mathrm{O}_{2}$.

The "H" group:

14. $\mathrm{Ha}=$ High-frequency dose of $\mathrm{H}_{2} \mathrm{O}_{2}$.

15. $\mathrm{Hb}=$ Midfrequency dose of $\mathrm{H}_{2} \mathrm{O}_{2}$.

16. $\mathrm{Hc}=$ Low-frequency dose of $\mathrm{H}_{2} \mathrm{O}_{2}$.

Each individual reservoir contained a recirculating pump which operated $24 \mathrm{~h} / \mathrm{d}$ (LIFETECH AP1000 aquarium pump AC220$240 \mathrm{~V}, \mathrm{H}: 0.65 \mathrm{~m}, 400 \mathrm{~L} / \mathrm{h})$, in the vortex treatments this pump was fitted to the vortex device, in the others the pumps were not connected to any piping. The pump curve specifications were used to determine the head and flow-rate relationship, the pumps were adjusted to account for the head of pressure required to lift water into the funnels while still maintaining a homogenous flow rate with the other treatments.

\section{Oxygenation Technology}

Vortex oxygenation. An annotated diagram of the DWC with a vortex oxygenator is shown in Fig. 1. Each vortex oxygenation device was constructed by inserting a plastic funnel (A) (300-mm long, with $200 \mathrm{~mm}$ opening at the base tapering to $32-\mathrm{mm}$ hole at the opposite end), with the larger opening facing upwards, into a PVC pipe (E) (110-mm diameter) which provided structural support. A LIFETECH AP1000 aquarium pump (D) placed at the bottom of the PVC support was attached to a 700-mm length of class $\mathrm{C}$ low density polyethylene (LDPE) with a diameter of $15 \mathrm{~mm}$ (B) that was secured to the outside of the funnel. Two $15-\mathrm{mm} 90^{\circ}$ elbows were attached to the end of this length of pipe and fed through the upper part of the funnel at an angle to deliver nutrient solution tangentially; this pipe is referred to as the inlet. At the lowest part of the funnel, a $25-\mathrm{mm}$ gate valve $(\mathrm{C})$ restricted the flow of solution as it drained from the funnel (this is referred to as the outlet); by manually adjusting this valve, the formation of vortices in the solution was facilitated. Another length of LDPE (12-mm diameter) was fitted $27 \mathrm{~mm}$ below the inlet and functioned as an over-flow (L), when setting the rate of flow through the outlet and during periods of low atmospheric pressure, a rise in the level of the solution within the funnel occurred-the over-flow pipe directed surplus solution back into the reservoir directly.

Air-pump specification. DARO twin aquarium air-pumps (DARO, Stikland Industria, Bellville) were used to supply oxygen to the solution of treatments specified previously. The air-pumps were connected to two "air-stone" dispersers within each of the selected treatment reservoirs with flexible LDPE tube.

Hydrogen peroxide $\left(\mathrm{H}_{2} \mathrm{O}_{2}\right) . \mathrm{H}_{2} \mathrm{O}_{2}(33 \%)$ was sourced from SCIENCEWORLD (Parow Industrial, Cape Town). Low-frequency dosage of $\mathrm{H}_{2} \mathrm{O}_{2}$ was applied at a rate of $1.7 \mathrm{~mL} \cdot \mathrm{L}^{-1}$ of solution only during the replacement of

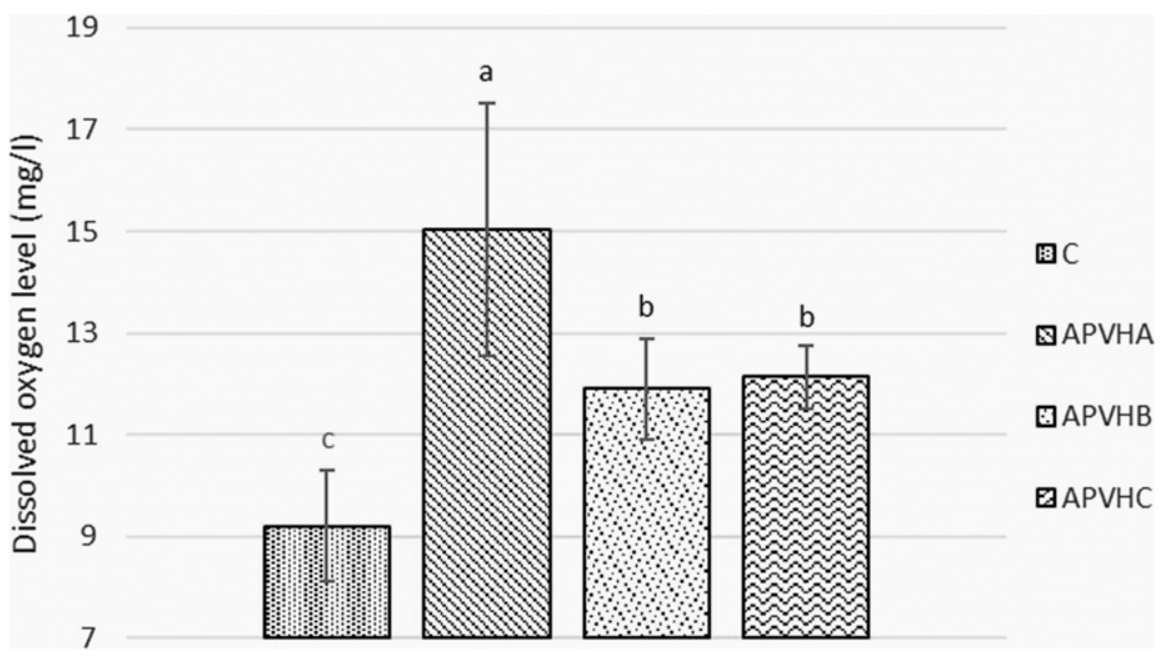

Fig. 3. Effects of treatments $11\left(\mathrm{APVHa}=\right.$ air-pump, vortex oxygenator plus high-frequency dosage of $\left.\mathrm{H}_{2} \mathrm{O}_{2}\right)$, $12\left(\mathrm{APVHb}=\right.$ air-pump, vortex oxygenator plus midfrequency dosage of $\left.\mathrm{H}_{2} \mathrm{O}_{2}\right)$, and $13(\mathrm{APVHc}=$ airpump, vortex oxygenator plus low-frequency dosage of $\mathrm{H}_{2} \mathrm{O}_{2}$ on the level of dissolved oxygen compared with that of the control (treatment 1 ). Bars indicate mean values \pm SD. The mean values represented by the bars annotated with different letters differ significantly at $P \leq 0.01$ as calculated by Fisher's least significant difference. The one-way ANOVA F-statistic is 5.513. 
nutrient solution, i.e., once every $9 \mathrm{~d}$. Midfrequency dosing was carried out every $4.5 \mathrm{~d}$. The high-frequency application of $\mathrm{H}_{2} \mathrm{O}_{2}$ occurred once every $3 \mathrm{~d}$; a dose was administered with the renewal of the solution, and twice again at 3-d intervals throughout the 9-d flush cycle.

\section{Determination of Plant Growth}

Chlorophyll content. At the end of the test period the chlorophyll content of the foliage of individual plants was measured by using nondestructive fluorometer analysis (Manetas et al., 1998). The CCM-300 chlorophyll meter produced by OPTI-SCIENCES, Inc. (Hudson, NH) uses a chlorophyll fluorescence ratio to measure the chlorophyll content within plant leaves (Opti-Sciences Inc., 2011). Two readings from separate, fully developed leaves of each plant were averaged and used to create data sets. A fiber-optic probe connected to an LED diode and two high sensitivity detectors enables this device to direct light at the leaf surface at one wavelength and measure the reemitted light (fluorescence) at another wavelength. Readings were obtained by holding the probe against the adaxial side of the leaves. The ratio between the fluorescence at $735 \mathrm{~nm}$ and within the range of 700-710 $\mathrm{nm}$ has been established as an accurate measure for determining the chlorophyll content within leaves (Gitelson et al., 1999), these are the wavelengths used by the CCM-300 to measure chlorophyll content (Marsh, 2016). A study conducted with another nondestructive chlorophyll measuring device, the SPAD-502 (Konica Minolta; Spectrum Technologies, Plainfield, IL) which used a similar mechanism of dual wavelength transmittance to measure chlorophyll content showed such apparatus was accurate even when used to measure pubescent leaves (Manetas et al., 1998).

Dissolved oxygen content. Once a week throughout the experimental period, the DO content within each treatment's reservoir was measured using an ORBECO HELLIGE series 150 multiparameter meter. The probe was inserted into the upper portion of the nutrient solution through an inspection hole in the lid. The DO probe was capped with a gas permeable membrane and contained an electrolyte solution which facilitated the formation of an electro-chemical gradient enabling the flow of oxygen from the aqueous solution once the probe was inserted. Within the probe were two electrodes which sensed the amount of electrical current passing through a charged wire before and after being exposed to the electrolyte mixture; the charge disturbance was indicative of the amount of oxygen. This meter is capable of measuring oxygen concentrations within a range between 0 and $20 \mathrm{mg} \cdot \mathrm{L}^{-1}$ of water.

Statistical analysis. All data were analyzed using one-way analysis of variance (ANOVA), using the computing software program STATISTICA 13. The occurrence of statistical difference was determined by

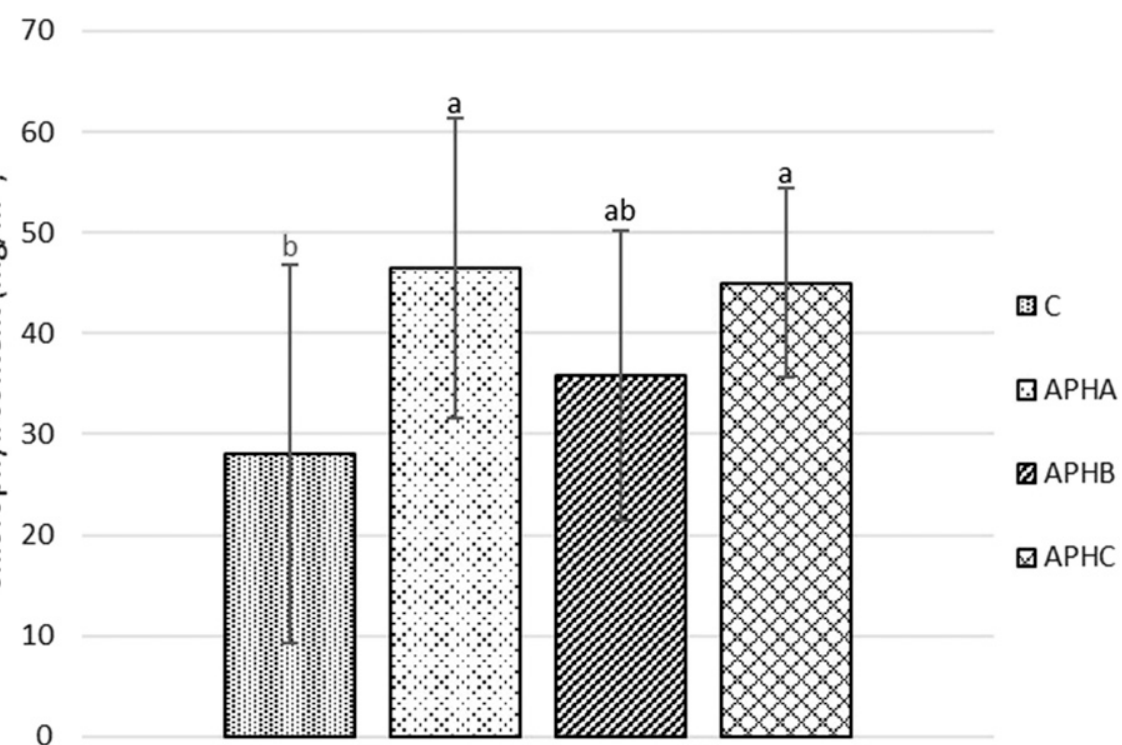

Fig. 4. Effects of air-pumps combined with various frequency dosing of hydrogen peroxide treatments 8 (APHa; high-frequency dosage), 9 (APHb; midfrequency dosage), and 10 (APHc; low-frequency dosage) on the chlorophyll content compared with the control (treatment 1). Bars indicate mean values $\pm \mathrm{SD}$. The mean values represented by the bars annotated with different letters differ significantly at $P \leq 0.05$ as calculated by Fisher's least significant difference. The one-way ANOVA F-statistic is 3.049.

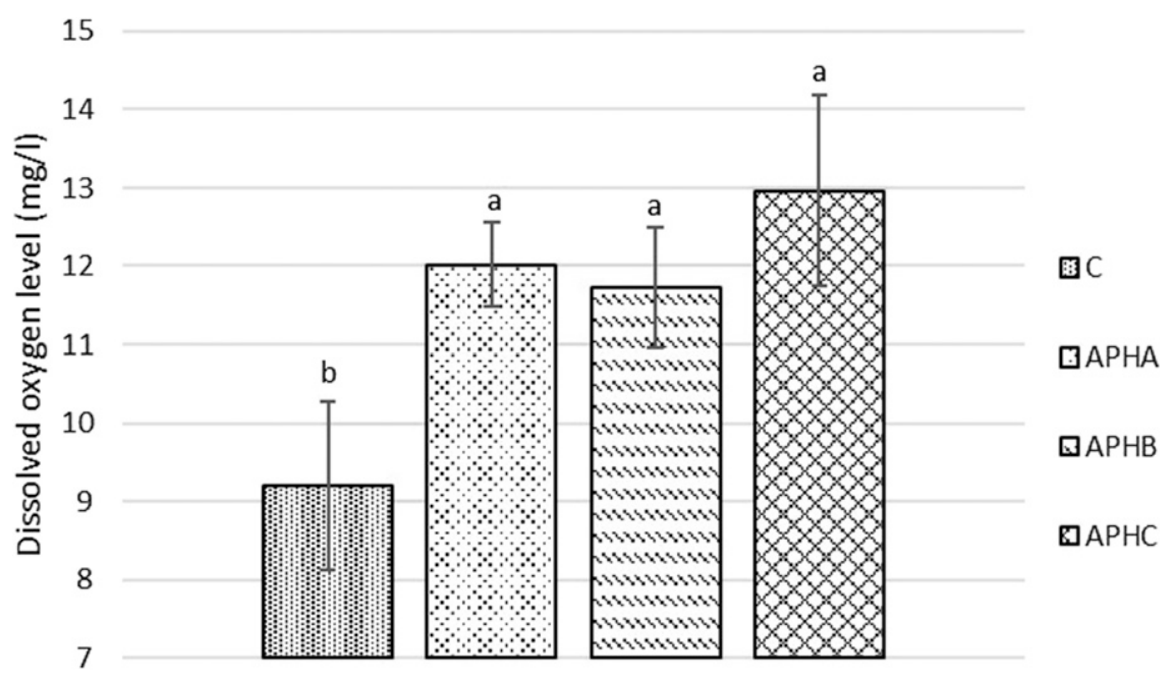

Fig. 5. Effects of air-pumps combined with various frequency dosing of hydrogen peroxide treatments 8 (APHa; high-frequency dosage), 9 (APHb; midfrequency dosage) and 10 (APHc; low-frequency dosage) on the level of dissolved oxygen compared with that of the control (treatment 1). Bars indicate mean values \pm SD. The mean values represented by the bars annotated with different letters differ significantly at $P \leq 0.05$ as calculated by Fisher's least significant difference. The one-way ANOVA F-statistic is 14.647.

using the Fisher's least significant difference at values of $P \leq 0.05, P \leq 0.01$, and $P \leq$ 0.001 levels of significance (Steel and Torrie, 1980).

\section{Results and Discussion}

The APVH group. The chlorophyll content readings for the APVH group (treatments 11/APVHa, 12/APVHb, and 13/APVHc) and the control (treatment 1) are shown in Fig. 2. The plants in the APVHa (treatment 11) had the highest mean value; the readings indicate significant difference $(P \leq 0.001)$ between this treatment, the control, and the other treatments. Treatments 12 (APVHb) and 13 (APVHc) were higher than $(10 \%$ and $35 \%$, respectively), although not significantly different from the control. Considering chlorophyll production has been shown to correlate (Marsh, 2016), the increased level of chlorophyll detected in these plants indicates they were more vigorous and metabolically active. This could be attributed to the significantly higher $(P \leq 0.01)$ level of DO content (Ehret et al., 2010; Kessler, 2015) within the nutrient solution (Fig. 3) facilitated by the combination of pressurized air injection (air-pump), a vortex oxygenator, and high-frequency with $N$ accumulation and overall plant health 
dosing with $\mathrm{H}_{2} \mathrm{O}_{2}$. There was no significant difference detected between the water temperatures or EC levels of the different treatments (data not shown) which indicates that differences in DO were a direct result of the various methods used to oxygenate the solution. A study conducted by Shete et al. (2013) on spinach plants grown in an aquaponics system showed that chlorophyll production increased with longer periods of mechanical circulation of the nutrient solution; the turbulence within the solution of the treatments may have had a similar effect in the present study. Turbulence created by the combination of air-pumps and vortex devices would also have affected the amount of gaseous exchange between the nutrient solution and the atmosphere by exposing a higher proportion of the solution to the surface gasliquid interface (Morse and Kytömaa, 2011; Peng et al., 1995). The increased level of mixing within these reservoirs discouraged stratification in the solution, thereby, avoiding the occurrence of oxygen-deficient zones and a loss in water quality (Chapman, 1996; Oppenheimer, 2008).

The APH group. Statistical difference $(P \leq$ 0.05 ) was found in the APH group (treatments 8/APHa, 9/APHb, and 10/APHc) when compared with the control as shown in Fig. 4. APHa (treatment 8) and APHc (treatment 10) had significantly $(P \leq 0.05)$ higher chlorophyll content than the control. Treatment 9 (APHb) yielded slightly higher (21\%) chlorophyll content readings than the control plants, however, did not differ significantly. Treatment 10 (APHc) yielded the highest mean within the group; these readings correspond with the elevated levels of DO displayed in Fig. 5, which indicates this treatment had the highest level of DO and differed significantly $(P \leq 0.05)$ to the control. Both other treatments (APHa and APHb) had significantly $(P \leq 0.05)$ higher DO levels than the control, however, yielded lower DO levels than treatment 10 (APHc). Soybean and rice plants grown in aerated solution (by using airpumps) in a test carried out by Boru et al. (2003) showed higher levels of chlorophyll content than those grown in nonaerated solution which supports the findings of the current study. Three cultivars of spinach were grown in an experiment conducted by Tesi et al. (2003) where two methods of oxygenating the nutrient solution (1) air injection by an air-pump and 2) mechanical circulation of solution through pump and length of pipe returning the solution at the surface of the reservoir] were compared with a nonoxygen enriched control. Both methods yielded plants which had significantly higher levels of chlorophyll than those from the control in the summer crop test. Results of the current experiment agree with these findings.

The $H$ group. Figure 6 indicates significant $(P \leq 0.05)$ difference between the chlorophyll content in the plants from treatment $14(\mathrm{Ha})$ and those from the control. Treatment $15(\mathrm{Hb})$ and $16(\mathrm{Hc})$ both showed higher chlorophyll content means $(31 \%$ and $31.5 \%$, respectively) than the control, however, they did not differ significantly. The group of treatments; Ha (treatment 14), $\mathrm{Hb}$ (treatment 15), and $\mathrm{Hc}$ (treatment 16) all differed significantly $(P \leq 0.05)$ from the control but were not significantly different from one another when DO was measured (data not shown). Although treatment 14 (Ha) had a DO mean value of only $2.84 \mathrm{mg} \cdot \mathrm{L}^{-1}$ higher than treatment $16(\mathrm{Hc})$, the variance indicated by the error bar for treatment $14(\mathrm{Ha})$ was the largest among the treatments (Fig. 7). At certain points throughout the experiment, treatment $14(\mathrm{Ha})$ had DO levels of $23.05 \mathrm{mg} \cdot \mathrm{L}^{-1}$ which may explain why the chlorophyll readings from this treatment were significantly higher than the control,

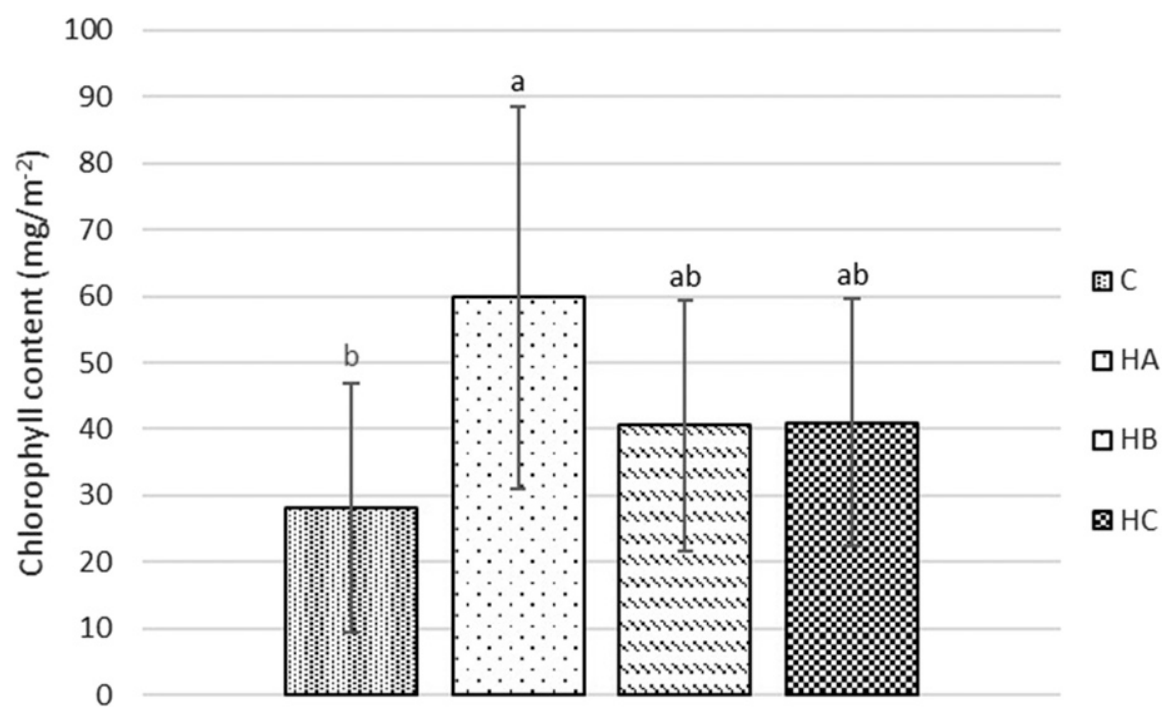

Fig. 6. Effects of various frequency dosing of hydrogen peroxide treatments 14 (Ha; high frequency), 15 ( $\mathrm{Hb}$; midfrequency), and 16 (Hc; low frequency) on the chlorophyll content compared with the control (treatment 1 ). Bars indicate mean values $\pm \mathrm{SD}$. The mean values represented by the bars annotated with different letters differ significantly at $P \leq 0.05$ calculated by Fisher's least significant difference. The one-way ANOVA F-statistic is 3.266.

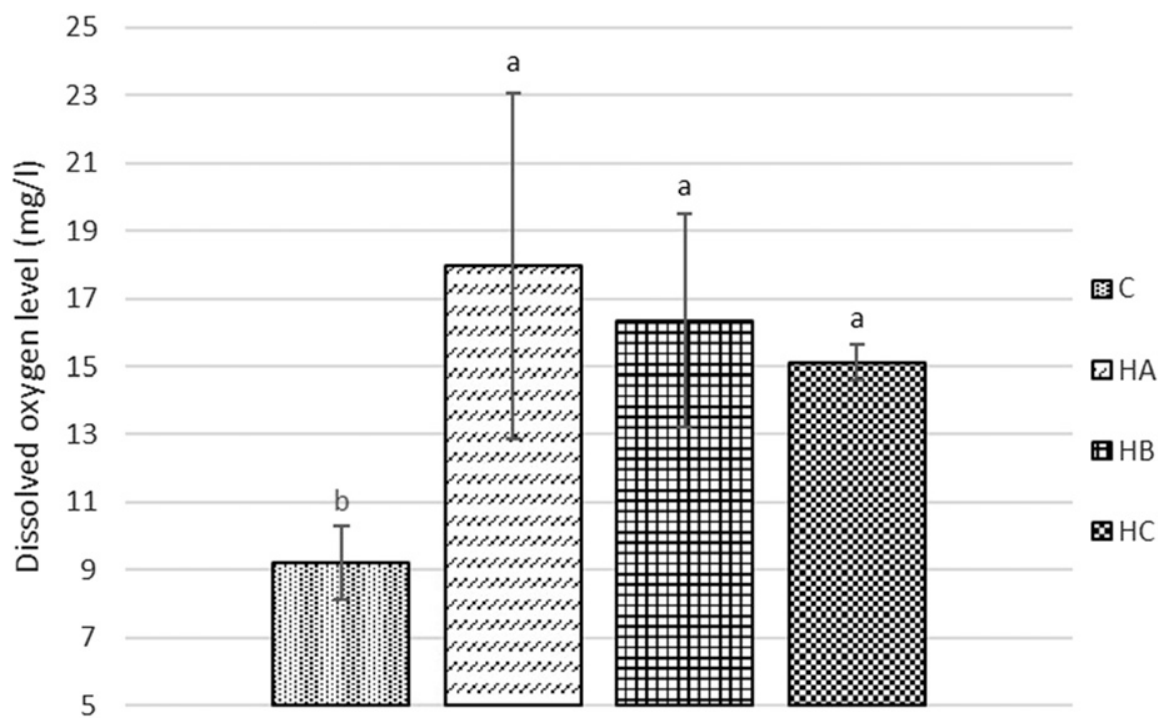

Fig. 7. Effects of various frequency dosing of hydrogen peroxide treatments 14 (Ha; high frequency), 15 ( $\mathrm{Hb}$; mid frequency), and 16 (Hc; low frequency) on the level of dissolved oxygen compared with the control (treatment 1 ). Bars indicate mean values \pm SD. The mean values represented by the bars annotated with different letters differ significantly at $P \leq 0.01$ calculated by Fisher's least significant difference. The one-way ANOVA F-statistic is 7.8483. 
(data not shown). Comparison of the chlorophyll content readings measured in the pure group (treatments $2 / \mathrm{V}, 3 / \mathrm{AP}$, and 4/APV) and the control indicated that none of these treatments yielded results of significant difference (data not shown). None of these treatments showed any significantly different levels in DO (data not shown) to the control.

\section{Conclusion}

The highest chlorophyll content mean value was achieved through a combination of high-frequency application of $\mathrm{H}_{2} \mathrm{O}_{2}$, an air-pump, and vortex oxygenation (treatment 11/APVHa). Although treatment $14(\mathrm{Ha})$ had the highest level of DO, the mean chlorophyll content value was slightly lower than treatment 11 (APVHa) and had a larger variance. These results indicate that to produce more photosynthetically active $P$. tomentosum plants in DWC hydroponics, it is advisable that application of high-frequency dosing of $\mathrm{H}_{2} \mathrm{O}_{2}$ be combined with other methods of oxygenation; when used with air-pumps (treatment 8/APHa) significantly higher content of chlorophyll was produced although not as high as when combined with an air-pump and vortex oxygenation. The increase in chlorophyll content could affect the essential oil yield; additional testing is required to establish the link between chlorophyll content and the production of essential oils in $P$. tomentosum.

\section{Literature Cited}

Ben-Yaakov, S. and Y. Ben-Asher. 1982. Continuous measurements of dissolved oxygen in water culture by a self-calibrating monitor. Water Res. 16:169-172.

Bonachela, S., J.A. Vargas, and R.A. Acuña. 2005. Effect of increasing the dissolved oxygen in the nutrient solution to above-saturation levels in a greenhouse watermelon crop grown in perlite bags in a Mediterranean area. Acta Hort. 697(1): 25-32.

Boru, G., T. Vantoai, J. Alves, D. Hua, and M. Knee. 2003. Responses of soybean to oxygen deficiency and elevated root-zone carbon dioxide concentration. Ann. Bot. 91:447-453.

Boudaghpour, S. and S. Hasemi. 2008. A study on light expanded clay aggregate (LECA) in a geotechnical view and its application on a greenhouse and greenroof application. Intl. J. Bot. 4(2):59-63.

Chapman, D.V. (ed.). 1996. Water quality assessments: A guide to the use of biota, sediments, and water in environmental monitoring. 2nd ed. Univ. Press, Cambridge, UK.

Cheeseman, J.M. 2007. Hydrogen peroxide and plant stress: A challenging relationship. Plant Stress. 1:4-15.

Chen, X., J. Dhungel, S.P. Bhattarai, M. Torabi, L. Pendergast, and D.J. Midmore. 2011. Impact of oxygation on soil respiration, yield and water use efficiency in three crop species. J. Plant Ecol. 4(4):236-248.

Demarne, F.E. and J.J.A. Van der Walt. 1990. Pelargonium tomentosum: A potential source of peppermint-scented essential oil. South African J. Plant Soil. 7:36-39.

Douglas, J.S. 1970. Hydroponics: The Bengal system. 4th ed. Wiley, West Sussex, UK.
Earls, C. 1997. Re: What is the difference of vortex and venture effect? 10 Nov. 2016. <http://www. madsci.org/posts/archives/1997-12/876338758 Eg.r.html>.

Ehret, D.L., D. Edwards, T. Helmer, W. Lin, G. Jones, M. Dorias, and A.P. Padapoulos. 2010. Effects of oxygen-enriched nutrient solution on greenhouse cucumber and pepper production. Sci. Hort. 125(4):602-607.

Fredrickson, B. 2014. Hydrogen peroxide and horticulture. 24 July $2015 .<\mathrm{http}: / /$ www.quickgrow. com/gardening_articles/hydrogen_peroxide_ horticulture.html>.

Gitelson, A.A., C. Buschmann, and H.K. Lichtenthaler 1999. The chlorophyll fluorescence ratio F735/ F700 as an accurate measure of the chlorophyll content in plants. Remote Sens. Environ. 69(3): 296-302.

Harris, D. 1992. Hydroponics: The complete guide to gardening without soil. 1st ed. New Holland Publishing, London, UK.

Kepenyes, J. and L. Váradi. 2015. Chapter 21: Aeration and oxygenation in aquaculture. 25 June 2015.<http://www.fao.org/docrep/x5744e/ $\mathrm{x} 5744 \mathrm{e} 0 \mathrm{~m} \cdot \mathrm{htm}>$.

Kessler, D. 2015. Airing out the truth on dissolved oxygen in hydroponics. 24 July 2015 . <http:// www.just4growers.com/stream/hydroponicgrowing-techniques/airing-out-the-truth-ondissolved-oxygen-in-hydroponics.aspx $>$.

Khandaker, M.M., A.N. Boyce, and N. Osman 2012. The influence of hydrogen peroxide on the growth, development and quality of wax apple (Syzygium samarangense, [Blume] Merril \& L.M. Perry var. jambu madu) fruits. Plant Physiol. Biochem. 53:101-110.

Konica Minolta. 2015. Chlorophyll Meter SPAD-502Plus. 24 June 2015. <http://www. konicaminolta.eu/en/measuring-instruments/ products/colour-measurement/chlorophyll-meter/ spad-502plus/introduction.html>.

Lawrence, E. 2002. Pelargonium tomentosum Jacq. 8 June 2015. <http://www.plantzafrica. $\mathrm{com} /$ plantnop/pelargtomento.htm>

Ling, Q., W. Huang, and P. Jarvis. 2011. Use of a SPAD-502 meter to measure leaf chlorophyll concentration in Arabidopsis thaliana. Photosynth. Res. 107(2):209-214.

Manetas, Y., G. Grammatikopoulos, and A. Kyparissis 1998. The use of portable, non-destructive, SPAD 502 (Minolta) chlorophyll meter with leaves of varying trichome density and anthocyanin content. J. Plant Physiol. 153:513-516.

Marsh, B.H. 2016. An investigation of current potato nitrogen fertility programs' contribution to ground water contamination. Intl. J. Biol Biomol. Agr. Food Biotech. Eng. 10(3):128-134

Maxwell, K. and G.N. Johnson. 2000. Chlorophyll fluorescence - a practical guide. J. Expt. Bot. 345(51):659-668.

Misra, A., A.K. Srivastava, N.K. Srivastava, and A. Khan. 2005. Zn-acquisition and its role in growth, photosynthesis, photosynthetic pigments, and biochemical changes in essential monoterpene oil(s) of Pelargonium graveolens. Photosynthetica 43(1):153-155.

ModularHydro. 2011. Using hydrogen peroxide in a hydroponic system. 29 July 2015. $<$ http://www.modularhydro.com/ArticleLibrary/ UsingHydrogenPeroxideInHydroponics.html $>$.

Morimoto, T., T. Masuda, and H. Nonami. 1989. Oxygen enrichment in deep hydroponic culture improves growth of spinach. Envrion. Control Biol. 27(3):97-102.

Morse, T.L. and H.K. Kytömaa. 2011. The effect of turbulence on the rate of evaporation of LNG on water. J. Loss Prevent. Proc. 24:791-797.
Oppenheimer, J. 2008. Mix it up. 24 May 2015. $<$ http://www.pwmag.com/bleeding/mix-it-up. aspx>.

Opti-Sciences Inc. 2011. CCM-300 - The chlorophyll content meter for very small leaves \& difficult to measure samples. 19 Oct. 2016. $<$ http://www.optisci.com/assets/ccm300.pdf $>$.

Park, J.-S. and K. Kurata. 2009. Application of microbubbles to hydroponics solution promotes lettuce growth. HortTechnology 19: 212-215.

Peng, J., J.K. Bewtra, and N. Biswas. 1995. Effect of turbulence of selected organic compounds from water. Water Environ. Res. 67(1):101107.

Salisbury, F.B. and C.W. Ross. 1985. Plant physiology. 3rd ed. Wadsworth Publishing Company, CA.

Schröder, F.-G. and J.H. Lieth. 2002. Irrigation control in hydroponics, p. 263-298. In: D. Savvas and H. Passam (eds.). Hydroponic production of vegetables and ornamentals. Embryo Publications, Athens, Greece.

Schlemmer, M.R., D.D. Francis, J.F. Shanahan, and J.S. Schepers. 2005. Remotely measuring chlorophyll content in corn leaves with differing nitrogen levels and relative water content. Agron. J. 97:106-112.

Shete, A.P., A.K. Verma, R.S. Tandel, C. Prakash, V.K. Tiwari, and T. Hussain. 2013. Optimization of water circulation period for the culture of goldfish with spinach in aquaponic system. J. Agr. Sci. 5(4):26-30.

Soffer, H., D.W. Burger, and J.H. Lieth. 1990 Plant growth and development of Chrysanthemum and Ficus in aero-hydroponics: Response to low dissolved oxygen concentrations. Sci. Hort. 45:287-294.

Starke Ayres. 2015. Fertiliser manual. 22 July 2015. $<$ http://www.starkeayres.co.za/docs/Fertiliser\% 20Manual\%20(MARCH\%202013).pdf>.

Steel, R.G.D. and J.H. Torrie. 1980. Principle and procedures of statistics: A biometrical approach. 2nd ed. McGraw Hill, New York, NY.

Swamy, K.N. and S.S.R. Rao. 2009. Effect of 24-epibrassinolide on growth, photosynthesis, and essential oil content of Pelargonium graveolens (L.) Herit. Russ. J. Plant Physiol. 56(5):616-620

Tesi, R., A. Lenzi, and P. Lombardi. 2003. Effect of different O2 levels on spinach (Spinacia oleracae L.) grown in a floating system. Acta Hort. 614:631-637.

Urrestarazu, M. and P.C. Mazuela. 2005. Effect of slow release oxygen supply by fertigation on horticultural crops under soilless cultivation. Sci. Hort. 106:484-490.

van Kooten, O. and F.H. Snel. 1990. The use of chlorophyll fluorescence nomenclature in plant stress physiology. Photosynth. Res. 25:147150 .

Wójtowicz, P., M. Szlachta, and A. Kotowski. 2013. Measurement of air-water transfer of cylindrical vortex flow regulators at a recirculating system. Environ. Prot. Eng. 39(3):207215 .

YSI. 2015. The basics of chlorophyll measurement: Tech note. 22 July 2015. <https://www. ysi.com/File\%20Library/Documents/Technical $\% 20$ Notes/T606-The-Basics-of-ChlorophyllMeasurement.pdf $>$.

Zheng, Y., L. Wang, and M. Dixon. 2007. An upper limit for elevated root zone dissolved oxygen concentration for tomato. Sci. Hort. 113:162-165 